\title{
PEMBUATAN DAN KARAKTERISASI ARANG AKTIF DARI BAMBU APUS (Gigantochloa apus) DENGAN AKTIVATOR $\mathrm{H}_{3} \mathrm{PO}_{4}$
}

\author{
M. Manurung*, E. Sahara, dan P. S. Sihombing \\ Program Studi Kimia, Fakultas Matematika dan Ilmu Pengetahuan Alam, Universitas Udayana \\ Jalan Kampus Unud-Jimbaran, Jimbaran-Bali, Indonesia \\ *e-mail: manuntun_manurung@unud.ac.id
}

\begin{abstract}
ABSTRAK
Bambu apus adalah salah satu bahan kerajinan yang limbahnya sangat mudah didapatkan di Bali. Limbah ini dapat digunakan untuk membuat karbon aktif. Tujuan penelitian adalah untuk menentukan suhu optimum karbonisasi, waktu karbonisasi, dan konsentrasi asam fosfat optimum pembuatan arang aktif bambu apus (AABA). Selain itu, AABA dikarakterisasi mengikuti SNI-1995 untuk arang aktif, serta gugus fungsi AABA ditentukan menggunakan Spektroskopi- FTIR. Hasil penelitian menunjukkan bahwa karbonisasi pada

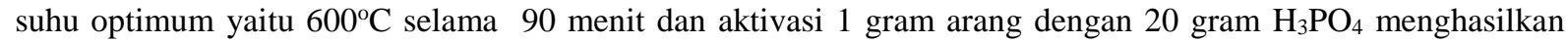
arang aktif yang memenuhi persyaratan SNI-199.dengan karakteristik sebagai berikut: Kadar air sebesar $(1,11 \pm$ $0,83 \%)$, kadar zat mudah menguap sebesar $(8,13 \pm 0,27 \%)$, kadar abu total sebesar $(7,33 \pm 1,35 \%)$, kadar karbon $(83,40 \pm 0,27 \%)$ serta daya serap terhadap iodin sebesar $1057,75 \mathrm{mg} / \mathrm{g}$ dan daya serap terhadap metilen biru $472,88 \mathrm{mg} / \mathrm{g}$. Identifikasi terhadap arang aktif dengan FTIR menunjukkan bahwa AABA mempunyai gugus fungsi, aromatik, keton dan hidroksi.
\end{abstract}

Kata kunci: arang aktif, bambu apus, $\mathrm{H}_{3} \mathrm{PO}_{4}$, karakterisasi

\section{ABSTRACT}

This paper discusses the manufacture and characterization of activated carbon from bamboo apus (Gigantochloa apus) with $\mathrm{H}_{3} \mathrm{PO}_{4}$ activator. The aims of study were to determine the optimum carbonization temperture and time as well as the amount of phosphoric acid required as the chemical activator. In addition, the activated carbon was also characterized following the Indonesian National Standard (SNI-1995) for activated carbon. Tthe activated carbon functional groups was determined using FTIR spectroscopy. The result showed that the optimum temperature of carbonization was $600^{\circ} \mathrm{C}$, the carbonization time was 90 minutes and the phosphoric acid required was 20 gram for 1 gram carbon. Under these conditions, the activated carbon resulted met SNI-1995 with the characteristics as follows: the water content was $(1.11 \pm 0.83 \%)$, the level of volatile substances was $(8.13 \pm 0.27 \%)$, the total ash amount was $(7.33 \pm 1.35 \%)$, the carbon contents was $(83.40 \pm 0.27 \%)$. and the absorption capacities of iodine and methylen blue were of $1057.75 \mathrm{mg} / \mathrm{g}, 472.88 \mathrm{mg} / \mathrm{g}$, respectively. FTIR identification indicated the existence of some functional groups, namely aromatik, ketone, and hydroxyl.

Keywords: activated carbon, bamboo apus, $\mathrm{H}_{3} \mathrm{PO}_{4}$, characterization

\section{PENDAHULUAN}

Tanaman bamboo apus atau bambu tali (Gigantochloa apus) adalah salah satu tanaman yang banyak tumbuh di Indonesia, termasuk di Pulau Bali. Masyarakat pedesaan, khususnya di Pulau Jawa dan Bali, memanfaatkan bambu untuk kerajinan dan bahan bangunan. Bambu apus mempunyai nama daerah yang beragam, di ataranya pring tali, pring apus (Jawa), awi tali (Sunda), tiing tali (Bali) dan pereng tale (Madura), (Wijaya, 2001). Industri kecil dan menengah telah memanfaatkan bambu sebagai bambu lapis( ply bamboo), kertas dan pulp serta menjadi bagian dari composite board. Pertumbuhan industri bamboo menimbul-kan masalah baru berupa limbah, seperti potongan bambu dan serbuk penggergajian (Supriyanto, 2001). Limbah bambu dapat diolah menjadi arang aktif. Arang aktif merupakan adsorben yang popular dan penggunaannya sangat beragam, misalnya sebagai adsorben zat warna pada pemurnian gula, pengolahan limbah dan bidang kesehatan (Subandrio, 2003).

Arang aktif dapat dihasilkan dari bahan-bahan yang mengandung karbon tinggi, melalui karbonisasi pada suhu tinggi tanpa oksigen (Miranti, 2012). Arang aktif adalah arang hasil karbonisasi yang di aktivasi secara fisika atau kimia atau gabungan keduanya. Arang aktif mempunyai kadar karbon berkisar $65-95 \%$ dan luas permukaan dapat mencapai 
300-3500 $\mathrm{m}^{2} / \mathrm{g}$ (SNI,1995, Chand et al., 2005). Aktivasi arang secara fisika dilakukan dengan cara mengalirkan uap air atau $\mathrm{CO}_{2}$, atau gas $\mathrm{N}_{2}$ pada suhu $900^{\circ} \mathrm{C}$ selama periode waktu tertentu. (Jamiatun et al.,2014). Aktivasi kimia dilakukan dengan merendam arang ke dalam activator bahan kimia seperti $\mathrm{HCl}$, $\mathrm{HNO}_{3}, \mathrm{Ca}(\mathrm{OH})_{2}, \mathrm{CaCl}_{2}, \mathrm{MgCl}_{2}, \mathrm{NaCl}, \mathrm{KOH}$, $\mathrm{H}_{3} \mathrm{PO}_{4}, \mathrm{Ca}_{3}\left(\mathrm{PO}_{4}\right)_{2}$ dan $\mathrm{ZnCl}_{2}$ ( Li et al., 2008). Srinivasakannan dan Bahar, (2004), melaporkan bahwa activator $\mathrm{H}_{3} \mathrm{PO}_{4}$ lebih banyak digunakan untuk mengaktivasi bahan yang mengandung lignoselulosa, termasuk bambu. Suhu, lamanya aktivasi dan juga jenis activator yang digunakan berpengaruh terhadap kualitas arang aktif yang dihasilkan (Ip et. al., 2008).

Pada penelitian ini dilakukan pembuatan arang aktif dari bambu apus (tiing tali) asal Bali dengan activator $\mathrm{H}_{3} \mathrm{PO}_{4}$. Pemilihan asam fosfat, karena merupakan asam lemah dan dianggap tidak mempengaruhi strruktur kristal arang aktif. Untuk mendapatkan hasil terbaik, dilakukan optimasi terhadap suhu karbonisasi/ karbonisasi, konsentrasi $\mathrm{H}_{3} \mathrm{PO}_{4}$ dan waktu karbonisasi. Selain itu, juga diperiksa gugus fungsi yang terdapat pada arang aktif menggunakan spektrofotometer FTIR.

\section{Bahan}

\section{METODE PENELITIAN}

Bahan yang digunakan untuk penelitian ini adalah limbah batang bambu apus/tali dari Desa Pempatan, Rendang, Karang asem, Bali. $\mathrm{H}_{3} \mathrm{PO}_{4}$, aquades, larutan Iodin $\left(\mathrm{I}_{2}\right), \mathrm{Na}_{2} \mathrm{~S}_{2} \mathrm{O}_{3}$, amilum, metilen biru.

\section{Peralatan}

Peralatan yang digunakan adalah neraca analitik, ayakan 212 mesh, cawan porselin, kaca arloji, oven, desikator, kertas saring Whatman no.40, pemanas, pengaduk magnet, $\mathrm{pH}$ universal, buret, peralatan gelas, stopwatch, UV-1800 dan Spectrofotometer Shimadzu FTIR Prestige-1,Tanur.

\section{Cara Kerja}

\section{Preparasi sampel}

Limbah batang bambu di potong kecikecil ,dicuci dengan air mengalir, dicacah dan dihaluskan, dicuci kembali kemudian dikeringkan dalam oven pada suhu $105^{\circ} \mathrm{C}$ hingga bobotnya konstan.

\section{Optimasi suhu karbonisasi/karbonisasi}

Sebanyak 50 gram sampel kering dengan kode (Ao) dimasukkan dalam cawan lalu dipanaskan dengan variasi suhu 300, 400, 500, 600 , dan $700^{\circ} \mathrm{C}$, selama $1 \mathrm{Jam}$. Masing-masing sampel didinginkan, ditimbang hingga bobotnya konstan, kemudian ditentukan rendemen dan kadar karbon masing-masing. Suhu optimum yang digunakan selanjutnya adalah suhu yang menghasilkan arang yang memberikan kadar karbon tertinnggi, dan memenuhi standar SNI-1995.

\section{Optimasi waktu karbonisasi}

Setelah didapatkan suhu optimum, selanjutnya dilakukan karbonisasi dengan berbagai waktu yaitu $1 ; 1,5 ; 2 ; 2,5$ dan 3 jam. Selanjutnya hasil karbonisasi dikarakterisasi dan hasilnya dibandingkan dengan SNI-1995.

\section{Aktivasi Arang}

Arang yang terbentuk dengan kualitas terbaik,dihaluskan dan diayak dengan ayakan 212 mesh. Arang yang lolos digunakan untuk selanjutnya. Arang dibagi menjadi dua bagian yaitu sampel dengan kode $\left(B_{0}\right)$ untuk arang tanpa aktivasi dan $\left(\mathrm{B}_{\mathrm{A}}\right)$ untuk arang yang diaktivasi. Sampel $\left(B_{0}\right)$ sebanyak 1 gram hanya dipanaskan pada suhu $900^{\circ} \mathrm{C}$ (ABAF) selama 15 menit, sebagai pembanding. Sampel $B_{A}$ diaktifkan dengan $\mathrm{H}_{3} \mathrm{PO}_{4}$. Sebanyak 1 gram sampel $\mathrm{B}_{\mathrm{A}}$ ditimbang, masing-masing dimasukkan ke dalam 5 gelas kimia, kemudian ditambahkan $100 \mathrm{~mL} \quad \mathrm{H}_{3} \mathrm{PO}_{4}$ dengan kadar yang bervariasi yaitu $5 \%, 10 \%, 15 \%, 20 \%$, dan $25 \%$, dibiarkan selama 24 jam. Kemudian disaring dan dibilas dengan aquades hingga $\mathrm{pH}$ netral. Arang aktif tersebut dipanaskan pada suhu $900^{\circ} \mathrm{C}$ selama 15 menit, disebut ABAKF, didinginkan dan ditimbang. Rendemen dan parameter kualitas arang aktif lainnya dibandingkan dengan SNI-1995. Jumlah asam fosfat optimum adalah volume dan konsentrasi asam fosfat yang memberikan karakteristik yang memenuhi standar SNI.

\section{Karakterisasi Arang Aktif}

Prosedur analisis yang digunakan adalah mengacu pada SNI-06-37370-1995tentang arang aktif teknis yakni: 


\section{Kadar air}

Ditimbang masing-masing sebanyak 1 gram Bo ( $\mathrm{ABAF})$ dan $\mathrm{B}_{\mathrm{A}}(\mathrm{ABAKF})$ dalam cawan porselin lalu dimasukkan ke dalam oven pada suhu $105^{\circ} \mathrm{C}$ sampai diperoleh bobot konstan, dinginkan, ditimbang hingga bobot konstan . Kadar air (KA) dihitung dengan persamaan berikut;

$$
\mathrm{KA}(\%)=\frac{(a-b)}{a} \times 100 \%
$$

$\mathrm{a}=$ berat karbon mula-mula (gram)

b. = berat karbon setelah pemanasan(gram).

\section{Kadar zat mudah menguap}

Sebanyak 4 gram arang (Bo) dan arang teraktifasi $\left(\mathrm{B}_{\mathrm{A}}\right)$ dipanaskan $800^{\circ} \mathrm{C}$ selama 15 menit, didinginkan dalam desikator selanjutnya ditimbang. Kadar zat yang mudah menguap (KZMM) dihitung dengan persamaan;

$$
\operatorname{KZMM}(\%)=\frac{(a-b)}{b} \mathrm{x} 100 \% \ldots \ldots \ldots \ldots(2)
$$

$\mathrm{a}=$ berat karbon mula-mula (gram)

$\mathrm{b} .=$ berat karbon setelah pemanasan(gram).

\section{Kadar abu total}

Sebanyak 1 gram arang Bo dan teraktifasi $\mathrm{B}_{\mathrm{A}}$ dimasukkan ke dalam cawan, dipanaskan pada suhu $105^{\circ} \mathrm{C}$, hingga berat konstan selanjutnya dipanaskan dalam tanur pada suhu $650^{\circ} \mathrm{C}$ selama 6 jam, hingga terbentuk abu, didinginkan dalam desikator, ditimbang,maka kadar abu total (KAT) dapat dihitung;

$$
\operatorname{KAT}(\%)=\frac{(\text { massa abu })}{(\text { massa arang })} \times 100 \% \ldots \ldots(3)
$$

\section{Kadar karbon} persamaan:

Kadar karbon (KK) dihitung dengan $\mathrm{KK}(\%)=100 \%-(\mathrm{KA}+\mathrm{KZMM}+\mathrm{KAT}) \ldots(4)$

\section{Adsorpsi Iodin}

Ditimbang sebanyak 0,25 gram arang (Bo) dan arang teraktifasi $\left(\mathrm{B}_{\mathrm{A}}\right)$ lalu dimasukkan ke dalam erlenmeyer, ditambahkan $25 \mathrm{~mL}$ larutan iodin $0,10 \mathrm{~N}$, diaduk selama 15 menit pada suhu kamar. Kemudian campuran disetrifugasi sampai terbentuk dua lapisan. $10 \mathrm{~mL}$ supernatan dipipet, dimasukkan ke dalam Erlenmeyer. Larutan dititrasi dengan larutan natrium tiosulfat menggunakan indikator amilum $1 \%$, hingga warna biru hilang.

\section{Adsorpsi metilen biru}

Ditimbang sebanyak 1 gram arang Bo dan $\mathrm{B}_{\mathrm{A}}$ ditambahkan ke dalam $200 \mathrm{~mL}$ larutan metilen biru $1000 \mathrm{ppm}$. Campuran diaduk dengan pengaduk magnet selama 10, 20, 40, 60 dan 90 menit. Larutan disaring dengan kertas saring Whatman 40, filtratnya diukur absorbansinya dengan UV-Vis pada panjang gelombang maksimum. Konsentrasi metilen biru yang tersisa dapat ditentukan dengan menggunakan persamaan regresi, Selanjut nya jumlah metilen biru yang teradsorpsi dapat dihitung.

\section{Analisis Gugus Fungsi}

Arang Bo dan Arang $B_{A}$ ditentukan gugus fungsinya menggunakan FTIR. Sampel arang dicampur dengan serbuk $\mathrm{KBr}$ digerus hingga homogen, lalu direkam spektrumnya. Hal yang sama diperlakukan untuk arang $B_{A}$. Hasil spektrum lalu dibandingkan dengan literatur.

\section{HASIL DAN PEMBAHASAN}

\section{Suhu dan waktu optimum Karbonisasi}

Pemotongan bambu menjadi bagian bagian kecil dimaksudkan untuk memudah kan proses karbonisasi. Tampilan sampel sebelum dan sesudah karbonisasi berbeda. Sebelum karbonisasi warna kuning, (a) dan setelah karbonisasi menjadi hitam mengkilap (b).

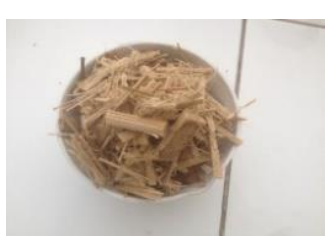

(a) awal

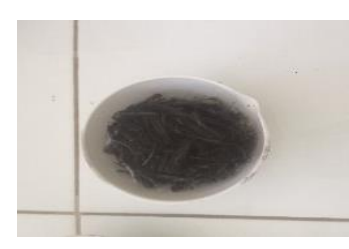

(b) akhir
Hasil karakterisasi terhadap arang yang dihasilkan pada proses pemanasan dari suhu $300^{\circ} \mathrm{C}$ hingga $700^{\circ} \mathrm{C}$, menunjukkan bahwa suhu optimum karbonisasi adalah $600^{\circ} \mathrm{C}$ karena dengan suhu ini dihasilkan arang yang memenuhi standar SNI-95, dengan rendemen $20,46 \%$ dan kadar karbon (KK) sebesar 68,87\% (Gambar 1, Tabel 1 berikut). 


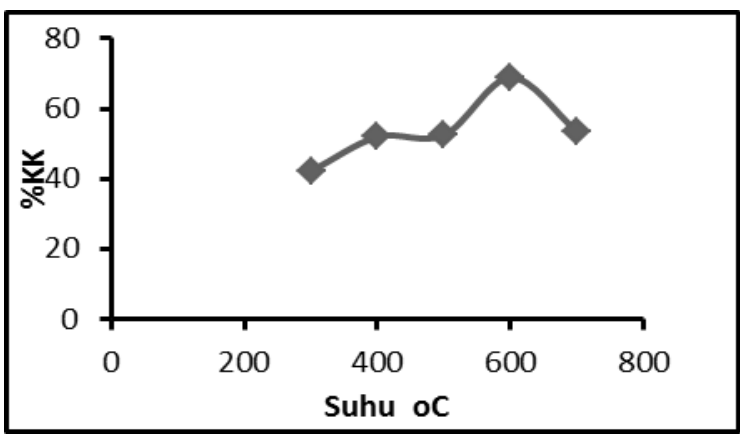

Gambar 1. Hubungan Kadar Karbon dengan suhu karbonisasi

Pada suhu yang lebih rendah, misalnya $400^{\circ} \mathrm{C}$ dan $500^{\circ} \mathrm{C}$ kadar karbon (KK) lebih rendah yaitu sekitar $52 \%$, dan pengotornya masih cukup tinggi yaitu sekitar $40 \%$ (Tabel 1.). Hal ini menunjukkan bahwa suhu tersebut belum cukup untuk melepaskan zat yang mudah menguap seperti tar, asam asetat, lignin (Jankowska, et al.,1991). Sedangkan waktu optimum karbonisasi pada suhu $600^{\circ} \mathrm{C}$ adalah 90 menit. Pemilihan kondisi ini didasarkan pada kadar karbon tertinggi dan syarat parameter SNI lainnya. Pada kondisi ini diperoleh rendemen sebanyak $18,92 \%$. Tinggi rendahnya rendemen karbon, dipengaruhi oleh suhu dan jenis bahan serta proses yang terjadi selama perlakuan.

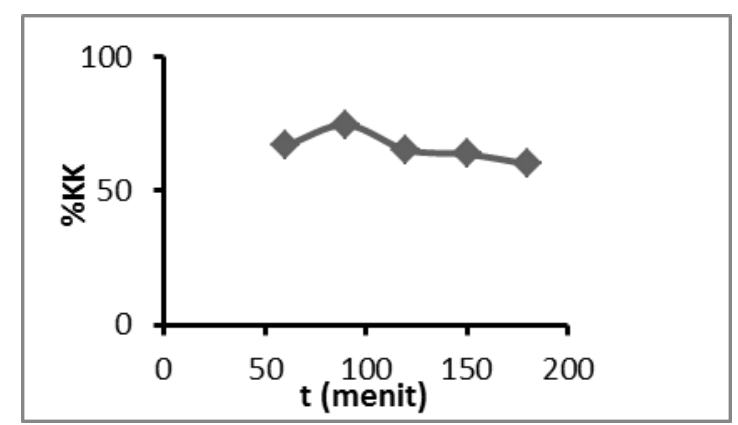

Gambar 2. Hubungan kadar karbon dengan waktu

Jika terjadi kontak dengan oksigen maka karbon akan berubah menjadi $\mathrm{CO}_{2}$ akibatnya rendemen kadar karbon menurun, tetapi tingkat kemurnian karbon aktif naik (Yue et al., 2003).

\section{Aktivasi arang}

Arang Bo hanya diberikan pemanasan pada suhu tinggi yaitu $900^{\circ} \mathrm{C}$, selama $1 \mathrm{jam}$ dalam tanur. Sedangkan arang $\mathrm{B}_{\mathrm{A}}$ direndam dalam $\mathrm{H}_{3} \mathrm{PO}_{4}$ dengan konsentrasi yang bervariasi dari 5 hingga $25 \%$, selama 24 jam, kemudian dipanaskan dalam tanur sama seperti arang Bo. Aktivasi terhadap 1 gram arang dengan $100 \mathrm{~mL} \mathrm{H}_{3} \mathrm{PO}_{4}, 20 \%$ arang dengan kadar karbon tertinggi yaitu $83,73 \%$ dan rendemen sebesar 22,38\% (Gambar 3, Tabel.3).

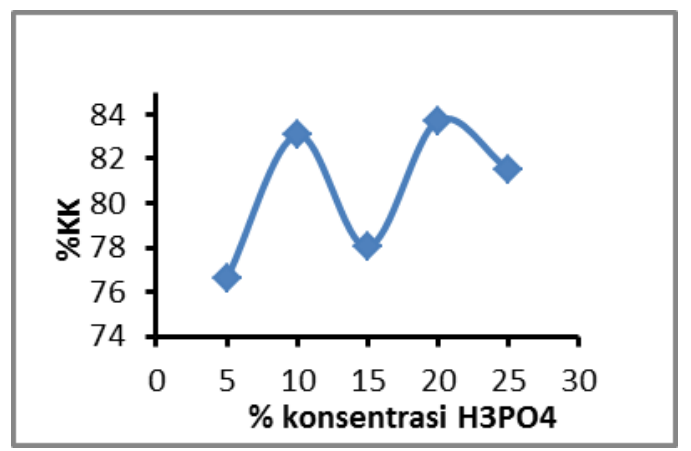

Gambar 3. Hubungan kadar karbon dengan persentasi asam $\mathrm{H} 3 \mathrm{PO} 4$

\section{Karakterisasi Arang aktif}

Hasil karakterisasi terhadap arang aktif (ABAKF) adalah sebagai berikut: kadar air rata-rata sebesar $1,11 \pm 0,83 \%$, kadar zat mudah menguap adalah $8,13 \pm 0,27 \%$, kadar abu total) sebesar $7,33 \pm 1,35 \%$, kadar karbon $83,40 \pm 0,27 \%$, daya serap terhadap iodin yaitu $1075 \mathrm{mg} / \mathrm{g}$ dan daya serap terhadap metilen biru $472,88 \mathrm{mg} / \mathrm{g}$. Hal yang sama dilakukan untuk Bo (ABAF) denga karakteristik sebagai berikut: kadar air sebesar 2,67\%; kadar zat mudah mengap sebesar 13,56\%, kadar abu total $12,88 \%$, kadar karbon sebesar $70,89 \%$, daya serap terhadap iodin dan metilen biru berturut-turut sebesar $1006,7 \mathrm{mg} / \mathrm{g}$ dan 382,38 $\mathrm{mg} / \mathrm{g}$. Dari karakteristik arang ABAF dan ABAKF terlihat dengan jelas bahwa proses aktivasi kimia lebih baik dibandingkan aktivasi fisika. Aktivator asam fosfat diduga mampu melarutkan pengotor tar, lignin, asam orgaik, oksida logam yang menutupi pori dan permukaan arang bambu (AB), sehingga mempunyai luas permukaan yang lebih besar. Hal ini ditandai dengan daya adsorpsi yang lebih besar terhadap Iodin dan metilen biru (Ni Putu Tejawati, et al., 2017 dan Jamilatun, et al., 2014). Berdasarkan SNI-06-37370-1995 tentang arang aktif teknis,dapat dikatakan bahwa arang aktif yang dihasilkan baik aktivasi Fisika (ABAF) dan ABAKF telah memenuhi kriteria arang aktif. Dari hasil spektroskopi FTIR terlihat bahwa baik ABAF dan ABAKF memiliki gugus fungsi yang sama yaitu cincin aromatik, karbonil, hidroksi dan 
eter, namun pada arang teraktivasi asam fosfat terlihat lebih tajam.

\section{SIMPULAN}

Berdasarkan penelitian yang dilakukan dapat disimpulkan;

1. Bambu apus (Gigantochloa apus) dapat dijadikan arang aktif dengan aktivator $\mathrm{H}_{3} \mathrm{PO}_{4}$.

2. Kondisi optimum pembuatan arang aktif yaitu suhu karbonisasi $600^{\circ} \mathrm{C}$, selama 90 menit dan jumlah asam fosfat yang dibutuhkan adalah 20 gram untuk setiap gram arang atau $100 \mathrm{~mL}$ asam forfat $20 \%$.

3. Karakteristik arang aktif yang dihasilkan yang teraktivasi fisika (ABAF) dan Kimia fisika (ABAKF) lebih baik dari SNI-063730-1995 untuk arang aktif teknis, untuk semua parameter.

\section{UCAPAN TERIMAKASIH}

Penulis mengucapkan terimakasih banyak pada staf Lab.Bersama FMIPA Universitas Udayana yang telah membantu kelancaran analisis dalam penelitian ini.

\section{DAFTAR PUSTAKA}

Badan Standarisasi Nasional,1995., Arang aktif teknis,BSN,Jakarta.

Chand, B.,Roop, and Meenakshi Goyal, 2005., Activated Carbon Adsorption, Taylor and Francis, Singapore.

Ip, A.W.M., Barford, J.P., McKay, G., 2008, Production and Comparison of High Surface Area Bamboo Derived Active Carbons. Bioresources Technol.9 9 (18): 8909-8916.

Jamilatun, S., Isparulita, D.I., Putri, E.N., 2014, karakteristik arang aktif dari temprung kelapa dengan pengaktivasi $\mathrm{H}_{2} \mathrm{SO}_{4}$, variasi suhu dan waktu. Simposium Nasional Teknologi Terapan, 2; 31-38.

Jankowska, H., Swiatkowski, A., dan Choma, J., 1991, Active Carbon, Horwood, London.

Li, W., Zhang, L. B., Peng, J. H., Li, N., Zhu, X. Y., 2008, Preparation of High Surface area Activated Carbons from Tobacco stems with $\mathrm{K}_{2} \mathrm{CO}_{3}$ actvation using Microwave Radiation, Ind.Crops Prod.,27:341-347.

Miranti, S. T., 2002, Pembuatan Karbon Aktif Dari Bambu Dengan Metode Aktivating Agent $\mathrm{H}_{3} \mathrm{PO}_{4}$ dan KOH, Skripsi, Fakultas Teknik Universitas Indonesia, Departemen Teknik Kimia , Depok.

Tejawati, N P., Manurung, M. dan Ratnayani, O., 2017, Karakterisasi ArangAktif Komersial serta Aplikasinya sebagaiAdsorben Ion Timbal(II) dan Krom(III), Jurnal Kimia,11(2):181-186.

Srinivasakannan, C., Bakar, M. Z. A., 2004, Pro duction of Activated carbon from Rubber Wood Sawdusti, Bomass Bioenergy, 27: 89-96.

Sudibandriyo, M., 2003, A Generalized OnoKondo Lattice Model for high Pressure on Carbon Adsorben, Dissertation, Oklahoma State University.

Sudrajat, R. dan Pari, G., 2011, Arang Aktif, Teknologi Pengolahan dan Masa Depannya, Badan Penelitian dan Pengembangan Kehutanan, Jakarta.

Supriyanto, A., 2001, Aplikasi Waste water Sludge untuk Proses pengom posan Serbuk Gergaji. Seminar on-air Biotek nologi untuk Indonesia Abad 21; 1-14. Sinergy Forum, PPI Tokyo Institut Of Technology.

Wijaya, E. A., 2001, Identitas Jenis-jenis Bambu di Kepulauan Sunda Kecil.Bogor Herbarium Bogoriense, Balitbang Botani, Puslitbang Boilogi-LIPI.

Yue, Z., Economy, J., dan Mangun, C. L., 2003, Preparation of Fibrous porous materials by Chemical Activation, Carbon, 41 : 1809-1817. 
Tabel 1. Data Penentuan Suhu Optimum Karbonisasi

\begin{tabular}{|c|c|c|c|c|}
\hline $\begin{array}{c}\text { Suhu } \\
\left({ }^{\circ} \mathrm{C}\right)\end{array}$ & $\begin{array}{c}\text { KA } \\
(\%)\end{array}$ & $\begin{array}{c}\text { KZMM } \\
(\%)\end{array}$ & $\begin{array}{c}\text { KAT } \\
(\%)\end{array}$ & $\begin{array}{c}\text { KK } \\
(\%)\end{array}$ \\
\hline 300 & 1,5754 & 52,0000 & 4,2553 & 42,1693 \\
400 & 1,9417 & 39,8009 & 6,3157 & 51,9417 \\
500 & 1,9047 & 37,0000 & 8,6021 & 52,4932 \\
$\mathbf{6 0 0}$ & $\mathbf{0 , 9 9 0 0}$ & $\mathbf{2 2 , 6 9 3 2}$ & $\mathbf{7 , 4 4 6 8}$ & $\mathbf{6 8 , 8 7 0 0}$ \\
700 & 1,9801 & 34,5000 & 10,000 & 53,5199 \\
SNI & Maks15 & Maks 25 & Maks10 & Min 65 \\
\hline
\end{tabular}

Keterangan : KA = kadar air;

KZMM = kadar zat mudah menguap;

$\mathrm{KAT}=$ kadar abu total ;

$\mathrm{KK}=$ kadar karbon .

Tabel 2. Data Penentuan Waktu optimum Karbonisasi

\begin{tabular}{|c|c|c|c|c|}
\hline $\begin{array}{c}\text { Waktu } \\
\text { (menit) }\end{array}$ & $\begin{array}{c}\text { KA } \\
(\%)\end{array}$ & $\begin{array}{c}\text { KZMM } \\
(\%)\end{array}$ & $\begin{array}{c}\text { KAT } \\
(\%)\end{array}$ & $\begin{array}{c}\text { KK } \\
(\%)\end{array}$ \\
\hline 60 & 4,9504 & 16,2094 & 11,9565 & 66,8837 \\
$\mathbf{9 0}$ & $\mathbf{2 , 0 0 0 0}$ & 12,1890 & 11,1111 & $\mathbf{7 4 , 6 9 9 9}$ \\
120 & 5,0000 & 16,7082 & 12,9032 & 65,3886 \\
150 & 3,9603 & 15,9600 & 16,3043 & 63,7754 \\
180 & 4,9019 & 14,7500 & 20,2127 & 60,1354 \\
SNI & $\begin{array}{c}\text { Maks } \\
\text { Maks 25 }\end{array}$ & Maks 10 & Maks 65 \\
\hline
\end{tabular}

Tabel.3. Data Optimasi Konsentrasi Aktivator $\mathrm{H}_{3} \mathrm{PO}_{4}$

\begin{tabular}{|c|c|c|c|c|}
\hline $\begin{array}{c}\text { Konsentr } \\
\text { asi } \\
(\%)\end{array}$ & $\begin{array}{c}\text { KA } \\
(\%)\end{array}$ & $\begin{array}{c}\text { KZMM } \\
(\%)\end{array}$ & $\begin{array}{c}\text { KAT } \\
(\%)\end{array}$ & $\begin{array}{c}\text { KK } \\
(\%)\end{array}$ \\
\hline 5 & 3,8834 & 14,2500 & 5,2631 & 76,6035 \\
10 & 3,3366 & 8,4788 & 5,1020 & 83,0826 \\
15 & 5,0000 & 10,4477 & 6,5217 & 78,0306 \\
$\mathbf{2 0}$ & $\mathbf{2 , 0 0 0 0}$ & $\mathbf{8 , 4 5 7 7}$ & $\mathbf{5 , 8 1 3 0}$ & $\mathbf{8 3 , 7 2 8 4}$ \\
25 & 2,9411 & 9,5000 & 6,0240 & 81,5349 \\
SNI & Maks 15 & Maks 25 & Maks 10 & Min 65 \\
\hline
\end{tabular}

Tabel 4. Karakterisasi Arang Aktif Terbaik

\begin{tabular}{|l|c|c|c|c|c|}
\hline & $\begin{array}{c}\text { Awal } \\
(\%)\end{array}$ & $\begin{array}{c}\text { I } \\
(\%)\end{array}$ & $\begin{array}{c}\text { II } \\
(\%)\end{array}$ & $\begin{array}{c}\text { Rerata } \\
(\%)\end{array}$ & SNI \\
\hline Rendemen & 22,3826 & 22,9508 & 20,9677 & $22,10 \pm 1,02$ & - \\
KA & 2 & 1 & 0,34 & $1,11 \pm 0,83$ & Maks 15 \\
KZMM & 8,4577 & 8 & 7,9610 & $8,13 \pm 0,27$ & Maks 25 \\
KAT & 5,8139 & 7,7777 & 8,4210 & $7,33 \pm 1,35$ & Maks 10 \\
KK & 83,7284 & 83,2223 & 83,2789 & $83,40 \pm 0,27$ & Min 65 \\
Absorpsi & 1057,75 & 1057,75 & 1057,75 & 1057,75 & Min 750 \\
I2(mg/g) & & & 472,88 & 472,88 & Min120 \\
Absorpsi & 472,88 & 472,88 & 470 & & \\
metilen & & & & & \\
biru & & & & & \\
(mg/g) & & & & & \\
\hline
\end{tabular}

Tabel 5. Karakteristik Arang Teraktivasi dan Arang Tanpa Aktivasi Asam Fosfat

\begin{tabular}{|c|c|c|c|c|}
\hline No & Karakteristik & Arang Bo (AABF) & $\begin{array}{l}\text { Arang } B_{A} \\
\text { (AABKF) }\end{array}$ & SNI \\
\hline 1. & $\% \mathrm{KA}$ & 2,6667 & 1,11 & Max 15 \\
\hline 2. & $\%$ KZMM & 13,5630 & 8,13 & Max 25 \\
\hline 3. & $\%$ KAT & 12,8787 & 7,33 & Max 10 \\
\hline 4. & $\% \mathrm{KK}$ & 70,8916 & 83,40 & Min 65 \\
\hline 5. & SerapanI $2(\mathrm{mg} / \mathrm{g})$ & 1006,97 & 1057,75 & Min 750 \\
\hline 6. & Serapan metilen Blue & 382,38 & 472,88 & Min 120 \\
\hline 7. & $\begin{array}{c}(\mathrm{mg} / \mathrm{g}) \\
\text { Gugus funsi }\end{array}$ & $\begin{array}{l}\text { Aromatik, karbonil, } \\
\text { eter, hidrokarbon }\end{array}$ & $\begin{array}{l}\text { Aromatik, karbonil, } \\
\text { eter, hidrokarbon }\end{array}$ & \\
\hline
\end{tabular}

